\title{
Disposal of pesticide waste from agricultural production in the Al-Batinah region of Northern Oman
}

\author{
Said Al Zadjali ${ }^{1,2}$, Stephen Morse ${ }^{2}$, Jonathan Chenoweth ${ }^{2}$ and Mike Deadman ${ }^{3}$ \\ ${ }^{1}$ Ministry of Environment and Climate Affairs, P O Box 32, 1 Muscat 100, Sultanate of Oman \\ ${ }^{2}$ Centre for Environmental Strategy, Faculty of Engineering and Physical Sciences, \\ University of Surrey, Guildford, Surrey, GU2 7JH, UK. \\ ${ }^{3}$ Department of Crop Sciences, College of Agricultural and Marine Sciences, Sultan Qaboos \\ University, P O Box 34, Al Khod 123, Sultanate of Oman.
}

\begin{abstract}
During the last two decades Oman has experienced rapid economic development but this has been accompanied by environmental problems. Manufacturing and agricultural output have increased substantially but initially this was not balanced with sufficient environmental management. Although agriculture in Oman is not usually considered a major component of the economy, government policy has been directed towards diversification of national income and as a result there has been an increasing emphasis on revenue from agriculture and an enhancement of production via the use of irrigation, machinery and inputs such as pesticides. In recent years this has been tempered with a range of interventions to encourage more sustainable production. Certain pesticides have been prohibited; there has been a promotion of organic agriculture and an emphasis on education and awareness programs for farmers. The last point is of especial relevance given the nature of the farm labour market in Oman and a reliance on expatriate and often untrained labour. The research, through a details stratified survey, explores the state of knowledge at farm-level regarding the safe disposal of pesticide waste and what factors could enhance or indeed operate against the spread and implementation of that knowledge. Members of the recently constituted Farmers Association were expressed environmentally awareness than their non-member counterparts in that they identified a more diverse range of potential risks associated with pesticide use and disposed of pesticide waste more in accordance with government policy, albeit government policy with gaps. Workers on farms belonging to Association members were also more likely to adhere to government policy in terms of waste disposal. The Farmers Association appears to be an effective conduit for the diffusion of knowledge about pesticide legislation and general awareness, apparently usurping the state agricultural extension service.
\end{abstract}

Keywords: pesticides, safety, Oman 


\section{Introduction}

It has been well established that problems associated with pesticide misuse and the inappropriate disposal of pesticide waste in developing countries can be attributed to a number of causes including lack of education and training in pesticide use and disposal; pesticide subsidies; lack or inadequate information on hazards; difficulty in conducting needed research due to fiscal constraints; problems of communication from state extension organisations; unwillingness of farmers to accept the risks of crop loss; the effect of the tropical climates; inadequate regulation and enforcement and gender issues (Levitan, 2000; Sibanda et al., 2000; Matthews et al., 2003; Atreya, 2007; Williamson et al., 2008). An important backdrop to this is that in many developing countries the development of pesticide policy and regulations does not have priority. But even if policy and regulations have been developed they alone cannot accomplish this objective unless they are both enforceable and are enforced (Schaefers, 1996). However, while these issues are well explored in the literature, there are questions that remain. One of these involves the interface between pesticide policy and implementation of that policy. It is, of course, a sine qua non that both of these are required for misuse to be minimised. Farah (1993) in an FAO survey indicated that about $25 \%$ of developing countries lack any kind of legislation to control the distribution and use of pesticide, and $80 \%$ lack the resources to implement and enforce the legislation that does exist. The latter point is of special concern but what structures are required to help facilitate implementation? It is this question that forms the basis for the research described here, and in particular how it could play out in one specific context - the Sultanate of Oman located in the southeast of the Arabian Peninsula. Oman provides a unique context with regard to pesticide misuse in a number of regards.

Oman has experienced a significant emphasis from its government on agriculture production. During the period 2001-2011 the growth rate of the total production of the principal crops grown in Oman was 1.5\% per year (faostat.fao.org, accessed 17 March 2013) and this has been facilitated in part by an increased use of pesticides. Small farms predominate with over $80 \%$ of the agricultural land occupied by farms with areas less than 2 hectares. Indeed agriculture is the main occupation of $65 \%$ of households. A wide range of crops are cultivated, most importantly dates (Phoenix dactylifera L.), lime (Citrus aurantifolia (Christm. \& Panzer) Swingle), mango (Mangifera indica L.), Rhodes grass (Chlorisg ayana Kunth) and alfalfa (Medicago sativa L.), and vegetables and other seasonal crops. However, despite the emphasis from government current agricultural production in 
Oman covers just one third of the country's food needs, making the country heavily dependent on imports. Agriculture and fisheries employ about 226,500 people, with close to $75 \%(169,600)$ of them being Omani (Al Zadjali, 2009). The number of agricultural labour wage earners is 72,155 of whom 15,000 (21\%) are Omani while the majority (57,000 or 79\%) are expatriate labourers mainly from India, Bangladesh and Pakistan (Al Zadjali, 2009). This balance is important as the expatriate labour force is generally low skilled and Al Zadjali (2009) has suggested that the low-skilled labour force in Oman is a significant factor contributing to the deterioration of natural resources, particularly soil and water, through extensive use of agrochemicals and irrigation water. It follows that if the level of skilling could be increased then it seems reasonable to assume that the detrimental impacts could be lessened.

There has been no lack of policy regarding pesticides in Oman; two fundamental Royal Decrees (primary legislation) relate to agricultural and industrial chemicals: Royal Decree 46/95 is concerned with industrial chemicals and pesticides whilst Royal Decree 64/06 is concerned with pesticide management. The 2006 Pesticides Law details types of pesticides and procedures for pesticide management and registration. The law specifically prohibits the use of certain pesticides perceived as most environmentally damaging. Based on the Pesticides Law, Ministerial Decision 194/07 provides details of prohibited and restricted pesticides. Under these legislations, 131 pesticides were prohibited from use in Oman. In addition, 30 were given restricted status meaning that certain pesticides can only be used at specified concentrations and formulations. Despite these recent actions, policy gaps remain, especially in relation to the disposal of empty pesticide containers and the disposal of unused but legal pesticides or stocks of now prohibited pesticides. Together these materials might be grouped as pesticide wastes. However while policies do exist, albeit with important gaps, the extent of their implementation has not been determined. Given the gap in policy concerning pesticide waste disposal and the potential shortfall in ability to enforce such legislation as exists, it becomes important to document current on-farm practices related to pesticides waste disposal. Such knowledge could have a major impact as part of future policy framing strategies. The current evaluation of on-farm practices is especially pertinent given the recent findings of widespread health issues within the farm labourer population of northern Oman linked to pesticide use in greenhouses (Esechie and Ibitayo, 2011). Oman does have an extension service, but this is often claimed to have serious limitations in terms of its effectiveness. Al Zadjali (2009) reports from interviews with focus groups from the 
agricultural sector in Oman that the state extension service suffers from insufficient staffing and a lack of training programmes such that farmers now have low confidence in the system, instead turning to the private sector for assistance. An alternative is to look at farmer-tofarmer $(\mathrm{F} 2 \mathrm{~F})$ as a means of achieving the same objective, but this requires knowledge regarding the extent of $\mathrm{F} 2 \mathrm{~F}$ and whether it already is helping to spread such 'best practice'. Oman provides an interesting context to explore this question as it has a number of Farmer Associations (FA) that in part are meant to help with the spread of such knowledge, but these associations are relatively recent arrivals on the scene. Nonetheless, it seems reasonable to assume that members and non-members of such FAs are likely to represent the ends of a spectrum in terms of safe pesticide usage.

The objective of the research described here was to explore the awareness of detrimental pesticide impacts and safe pesticide use by members and non-members of an FA in Oman, and to what extent can any differences be explained by the characteristics (education, age, land ownership) of these groups? It is the first research of its kind in Oman and, as far as we are aware, the first attempt to explore this within the region.

\section{Materials and methods}

\subsection{Study area}

The total area of Oman is $309,500 \mathrm{~km}^{2}$ with a total population estimated at 2.7 million and $50 \%$ of the population living in Muscat and the Al Batinah Governorates. Al Batinah is the main agricultural region in Oman, with $44.3 \%$ of the total production of the country (Anon, 2010). Given that the Al Batinah Governorates represent the most intensively farmed region of Oman, it was this area that provided the focus for the research. There are 10 Wilaya (administrative districts, sing. = Wilayat $)$ in the region and a single farmer's association $(\mathrm{FA})$ established under Ministerial Decision 126/2009 (Ministry of Agriculture and Fisheries Wealth) in 2009 as the Agricultural Association For Al-Batinah Farmers, a form of what Carney refers to as a Formal Farmer Organisation (Carney, 1996). It currently has 65 members; farmers apply to join the Association and pay a membership fee of approximately 20 US\$ per hectare per year. The primary objectives of the Association include increased access to new technology, encouragement of increased use of environmentally more benign pesticides, sustainable use of water resources and collective marketing of products. Thus it 
seems reasonable to hypothesise that FA members would be better informed in terms of good pesticide handling practices and that they would confer some of that to their farm workforce, at least relative to non-FA members.

$<$ Figure 1 near here>.

\subsection{Data collection and analysis}

A structured questionnaire was implemented through face to face interviews with 213 farm worker and farm owner respondents from 213 farms (randomly selected from those listed in the agricultural census database) in both Al-Batinah Governorates between January and November 2012 (but excluding the May - September summer months when agricultural activities are minimal). The respondents were divided into those from farms belonging to the recently constituted FA and those from non-FA farms. Within each group the respondents were divided into workers and owners in roughly equal proportion. 'Owners' here are defined as those who actually own the farm and derive the benefits from selling produce. They may not necessarily be resident on the farm. 'Workers' are in essence the labourers who work and, in most cases, live on the farm. In Oman the Ministry of Manpower guidelines indicate that 3 workers can be employed per ha of farmland. The worker respondents represented the 'foreman' or senior-most labourer present. Thus there were four categories of respondent in total:

(a) FA - farm owner

(b) FA - farm worker

(c) Non-FA - farm owner

(d) Non-FA - farm worker

The emphasis of the survey was to determine the extent of knowledge that respondents had regarding the detrimental effects of pesticides on human health and the environment, as well as the fate of empty pesticide containers and the method of disposal of unused expired pesticides products. Exploring differences in attitude between the owners of the land - those who might be thought to have a vested interest in its sustainable use, and 
those employed as essentially migrant workers - those without this vested interest was a key objective of the survey. General questions about the size of the farm and the labourer's age, nationality and education status, were also included so as to explore differences between the FA and non-FA categories and how this might explain any differences in knowledge and practice. The questionnaire was semi-structured in nature.

Data (percentage responses to questions) were analysed using Pearson's correlation coefficient. The objective was to identify any similarity in the pattern of response across the four categories of respondent listed above.

\section{Results}

\subsection{Sample description}

The profile of the sample, average farm size and average respondent age is shown in Table 1. Farm sizes of the respondents varied from less than 1 ha to over 500 ha, with an average of 16.8 ha. Respondent aged were between 23 and 72 years with an average of 44.1 . Owners and workers on FA farms were generally younger than those on non-FA farms and workers were generally younger than owners.

<Table 1 near here>

The nationalities of the worker respondents are shown in Table 2. Among the farm workers, Bangladeshi nationals represented the largest group in both FA and non-FA farms (87 in total, 40.8\%). All owners of FA and non-FA farms were Oman nationals. The educational background of the respondents is shown in Table 3. A considerable proportion of the respondents was uneducated $(44,20.7 \%)$ or had elementary education $(70,32.9 \%)$. Thirty one respondents (14.6\%) were educated to tertiary level. Workers from FA farms generally had higher levels of education than those from non-FA farms, and owners of farms belonging to the FA generally had a higher level of education than owners of non-FA farms. 
$<$ Tables 2 and 3 near here>

\subsection{Pesticide use}

When asked to identify specific risks associated with pesticide use from those listed on the survey form, $88.5 \%$ of workers from FA farms listed the risk to human health (Table 4). This compared to only $35.3 \%$ of workers from non-FA farms; $64.7 \%$ of this group also indicated that pesticide use came with no identifiable risk. Amongst the farm owners, a similar percent of respondents identified the hazard to human health from pesticide use (96.3\% and $92.7 \%$ from $\mathrm{FA}$ and non-FA farms respectively. A considerably greater percentage of owners from FA farms identified risk to the environment from pesticide use (70.4\%) compared to owners of non-FA farms (20.0\%). Over 9\% of owners of non-FA farms indicated that pesticide use posed no identifiable risk. Overall, risk to the consumer from pesticide use was the lowest ranked of the factors listed on the survey form $(0.9 \%$ of all respondents, Table 4). The correlation coefficient values for responses between the groups are shown in Table 5. These provide some interesting results. The correlations that suggest a similar response to the questions are between FA owners and non-FA owners $(r=0.826)$, although this is only significant at $\mathrm{P}<0.1$, and FA workers and non-FA owners $(\mathrm{r}=0.996$ $\mathrm{P}<0.001)$. The correlation between FA owners and FA workers is positive $(\mathrm{r}=0.772)$ but not statistically significant. The non-FA worker is the group that stands out as having least in common in terms of risk identification with the other three.

<Tables 4 and 5 near here>

Respondent's attitudes towards disposal of residual pesticide solutions and expired pesticides are shown in Table 6. FA farm workers were most likely to store expired pesticides $(78.8 \%)$ and to use completely a solution already mixed (98.1\%). Workers from non-FA farms, in contrast, were most likely to continue to use expired pesticides $(47.1 \%)$ and to dispose of mixed pesticide solutions in the soil $(58.8 \%)$ or by mixing these solutions with manure prior to disposal in the soil $(64.7 \%)$. The correlation coefficients for the patterns of 
response to this question across the four groups are shown in Table 7. There was no significant correlation between responses from FA farm workers and non-FA farm workers ( $\mathrm{r}$ $=-0.121)$. FA farm owner's responses were similar to those obtained from the FA farm worker group $(\mathrm{r}=0.687 \mathrm{P}<0.05)$, with the most frequent responses being that expired pesticides were stored $(90.7 \%)$ and that mixed pesticide solutions were used completely (61.1\%). In addition, FA farm owners appeared to seek advice from their FA when deciding about disposal issues $(79.6 \%)$. The non-FA farm owner responses were most similar to the non-FA worker responses $(\mathrm{r}=0.836 \mathrm{P}<0.01)$ with the majority of respondents stating that pesticide solutions are mixed with manure prior to disposal (58.9\%). There was no significant correlation between FA farm owners and non-FA farm owners $(r=0.089)$. Table 6 also indicates that very few respondents stated that they seek advice from the state extension service of the Ministry of Agriculture and Fisheries Wealth prior to making decisions about pesticide disposal. This reinforces a point made earlier in the introduction about the perceived effectiveness of the extension services in Oman.

<Tables 6 and 7 near here>

Clear differences in the pattern of response also emerged when farm workers were asked about the methods used to dispose of empty pesticide containers (Table 8). Respondents from FA and non-FA farms (workers and owners) overwhelmingly reported that empty containers were disposed of by placing in municipality garbage bins (FA) and by burning on-site (non-FA). The correlations between the patterns of response are shown in Table 9. There were significant correlations between responses of FA farm workers and FA farm owners $(\mathrm{r}=0.979, \mathrm{P}<0.001)$ and between non-FA farm workers and non-FA farm owners $(\mathrm{r}=0.931, \mathrm{P}<0.05)$. Response patterns between FA and non-FA farm workers and between FA farm owners and non-FA farm owners were not significantly correlated.

$<$ Tables 8 and 9 near here> 


\section{Discussion}

In the Al-Batinah Governorates of northern Oman FA farm owner respondents were younger than their non-FA farm counterparts, on average had a higher level of education and were owners of larger farms. These are important factors that no doubt would have an influence on their awareness of pesticide issues and knowledge of best practice when it comes to handling. Thus it is not possible to claim per se that membership of an FA had an impact on pesticide use, storage and disposal as members of the FA were more likely to be those who had such knowledge in the first place or a willingness to learn about such matters. Even so it is instructive to explore the differences between the two groups - FA and non-FA.

Not surprisingly, the hazard of pesticides to human health was identified by a number of the respondents to the survey. Indeed a majority of FA farm workers (88.5\%), FA farm owners $(96.3 \%)$ and non-FA farm owners $(92.7 \%)$ all claimed to be aware of the hazardous nature of these chemicals. However, the human health risk was identified by only a minority of workers from non-FA farms and this must be a cause for concern. The question must be asked as to why it is that FA farm owners and workers have this awareness yet while the nonFA owners also have it there is a failure for this awareness to be passed to their workers? Also of concern is the finding that within three out of the four groups of respondents surveyed (workers on FA and non-FA farms and owners of non-FA farms) the level of recognition that pesticides could pose a danger to the environment was equal to or less than $20 \%$. Only amongst the FA farm owners was a threat to the environment recognised by more than $70 \%$ of respondents. The mismatch between the FA farmer owners and their workers with regard to this danger to the environment is a surprise as one would have expected a degree of influence from the owners. Of even greater concern is the response from workers from non-FA farms where over $64 \%$ of respondents stated that the use of pesticides posed no danger whatsoever; either to people or to the environment. Admittedly this was the group with the highest level of respondents with no formal education. Indeed the $34 \%$ (from 213) of agricultural workers with no formal education represents a substantially larger group than Matthews (2008) found (16\%) in a survey of over 8500 small-scale farmers in 26 countries. However, these findings do broadly indicate a significant weakness in knowledge transfer between farm owners and workers in both FA and non-FA farm, but especially for the latter. 
The importance of education with regard to pesticide use is no surprise. In a study of the language and literacy barriers to health and safety training of agricultural workers in the USA, Arcury et al. (2010) state that a lack of education affects work-related health and safety training in three ways: (1) workers have limited literacy skills, (2) such workers lack the skills needed for learning and (3) their ability to learn complex concepts is limited. In the current context one might imagine that a lack of education would limit their ability to understand pesticide labels, follow instructions related to disposal of pesticides and conceptualize the consequences of poor pesticide disposal practices. Clearly, this group must be a particular target for future outreach activities to increase the skills base. Indeed the fact that less than $1 \%$ of all respondents indicated that pesticide use might pose a hazard for farm produce consumers is a further cause for concern and indicates, perhaps, a general ignorance of the importance of accuracy in determining the correct dosage of pesticide applications and concepts such as re-entry period and harvest interval.

Previous studies have examined the practices used by farmers in disposing of expired and obsolete pesticides. Amongst Greek farmers, Damalas et al. (2008) reported that a majority of farmers $(54.9 \%)$ typically use all of the available pesticide, leaving none for disposal. With regard to old pesticide stocks, the same study found that the most frequent responses were that this material was disposed of either by continuing to use (35.8\%), burning in their containers $(23.5 \%)$ or dumping $(16 \%)$. In the current study a large proportion of FA farm workers $(98.1 \%)$ and FA farm owners $(68.1 \%)$ similarly reported that they use all of the mixed pesticide solutions in one operation. This was not reflected in the responses from non-FA farms where workers mix left-over pesticide mixes either with manure or soil to dispose of them, whilst non-FA farm owners reported most frequently that mixes were disposed-of by mixing with manure which itself was then applied to the soil. As stated by Damalas et al. (2008) and others (for example Avory and Coggon, 1994; Ntow et al., 2006) disposing of pesticide residues on un-cropped areas (soil or manure destined to be mixed with soil in this study) poses a threat to groundwater and a hazard to humans, domestic animals and wildlife. The commonly reported practice by FA farm owners and workers of storing obsolete pesticide stocks is in line with current government policy as stated in the 2006 Pesticide Law which itself refers to previous legislation, specifically Ministerial Decision No. 18/93 (issued by the Ministry of Environment that states "Every hazardous waste generator shall store hazardous waste in approved storage facilities on his land or at his premises until its removal in accordance with the terms of the licence issued by the 
Ministry". The practice of FA farm owners of seeking the advice of the Association prior to disposal, whilst apparently eschewing the extension service of the Ministry of Agriculture and Fisheries Wealth appears to indicate that the FA is usurping the state extension service as a means of knowledge diffusion about pesticides and pesticide safety. This is reflected in further questions asked of the survey sample concerning sources of advice but not reported here.

When disposing of empty pesticide containers, the contrast in behaviour between workers and owners of FA farms and workers and owners from non-FA farms was clear. From FA farms, both owners and workers, a majority of respondents reported that empty containers are placed in municipality garbage bins. In contrast a majority of non-FA farm workers and owners reported that empty containers are burned on site. Again those from FA farms appear to be following government guidelines, although no clear policy exists for the effective disposal of pesticide containers since the content of municipality garbage bins are buried at land-fill locations. The on-farm burning of pesticide containers is frequently reported in farm surveys, especially in less developed countries including South Africa (15\% of respondents, Dalvie et al., 2006) and Tanzania (35\% of respondents, Nonga et el., 2011). In Greece Damalas et al., (2008) reported that $17.9 \%$ of responding farmers burnt empty containers on-site. The implications for public health and environmental damage from this practice are clear. In the current survey no respondents reported the re-use of empty pesticide containers. This positive response is welcome, especially since in other surveys as many as $18 \%$ (South Africa) and even 49.3\% (Ethiopia) indicate that empty containers are re-used for food or water storage (Dalvie et al., 2006; Amera and Abate, 2008).

In general the results suggest that of the four groups the FA farm owners were more aware of the risks of pesticide use and more likely to conform with government policy in the disposal of old pesticides and empty pesticide containers. Interestingly, FA farm workers, despite being approximately the same age as their non-FA farm counterparts and having similar ethnic backgrounds, gave responses that were usually more similar to FA farm owners than to non-FA farm workers, perhaps because of their generally higher level of education and a degree of influence/training from their employers. The non-FA farm workers had the lowest awareness of these important issues amongst all four respondent categories. However, a separation of the influence of being an FA member (for both owners and workers) from a background of 'better' education is not easy. One of the key benefits that accrues to FA members is better access to information, including farmer-to-farmer, and this is likely to 
attract those farmers who are inclined to want to farm effectively and responsibly. This may well be reflected in a desire to hire staff who have good knowledge of farming or who are willing to learn and adapt. Future research will attempt to resolve the issue of whether FA membership changes the attitudes of farm owners or is attractive to a membership with more environmentally enlightened outlooks to crop production and whether workers, by knowledge diffusion, are taking on the attitudes of the farm owner.

\section{Conclusions}

Pesticide waste disposal practices and awareness of the environmental and human hazards of pesticide use vary greatly within the farming community of the Al-Batinah Governorates of northern Oman. Within one section of the farm worker community over $64 \%$ of respondents believed that pesticide use posed no risk to human health or other indicators. Waste disposal practices generally showed a higher level of conformity to government guidelines where farmers were members of the local farmers association, although gaps in government policy indicate that environmental hazards still exist, especially in terms of the disposal of empty pesticide containers. As a source of information and knowledge about pesticide-related issues, farmers association members appear to rely on their own association rather than the state extension service.

\section{REFERENCES}

Al Zadjali KMS. Management of Agricultural Resources in the Sultanate of Oman (AlBatinah as Case Study). PhD Thesis 2009; The University of Reading, UK, 315pp.

Amera T, Abate A. An assessment of the pesticide use, practice and hazards in the Ethiopian rift valley. Institute for Sustainable Development, Africa Stockpiles Programme 2008; Annex 6:61pp.

Anon. Comprehensive Master Plan for Al-Batinah Coastal Area Phase-1 Final Report: Analysis and Assessment of Study Area. Supreme Committee for Town Planning, Sultanate of Oman, 2010. 
Arcury TA, Estrada JM, Quandt SA. Overcoming language and literacy barriers in safety and health training of agricultural workers. Journal of Agromedicine 2010;15:236-248.

Atreya K. Pesticide use knowledge and practices: A gender differences in Nepal. Environmental Research 2007;104:305-311.

Avory G, Coggon D. Determinants of safe behaviour in farmers when working with pesticides. Occupational Medicine 1994; 44:236-238.

Carney D. Formal farmers organisations in the agricultural technology system: Current roles and future strategies. ODI Natural Resource Perspectives 1996; Number 14.

General Census of Populations, Housing and Establishment 2010.

Dalvie MA, Africa A, London L. Disposal of unwanted pesticides in Stellenbosch, South Africa. Science of the Total Environment 2006;361:8-17.

Damalas CA, Telidis GK, Thanos SD. Assessing farmers' practices on disposal of pesticide waste after use. Science of the Total Environment 2008;390:341-345.

Esechie JO, Ibitayo OO. Pesticide use and related health problems among greenhouse workers in Batinah coastal region of Oman. Journal of Forensic and Legal Medicine 2011;18:198-203.

Farah J. Pesticide policies in developing countries: Do they encourage excessive pesticide use? World Bank Discussion Paper No. 238, 1993; Washington, D.C., World Bank, 75pp.

Government of the Sultanate of Oman Gazette No. (2006/818).

Levitan L. "How to" and "why": assessing the enviro-social impacts of pesticides. Crop Protection 2000;19:629-636.

Matthews G. Attitudes and behaviours regarding use of crop protection products - A survey of more than 8500 smallholders in 26 countries. Crop Protection 2008;27:834-846.

Matthews G, Wiles T, Baleguel P. A survey of pesticide application in Cameroon. Crop Protection 2003;22:707-714. 
Nonga HE, Mdegela RH, Lie E, Sandvik M, Skaare JU. Assessment of farming practices and uses of agrochemicals in Lake Manyara basin, Tanzania. African Journal of Agricultural Research 2011;6:2216-1130.

Ntow WJ, Gijzen HJ, Kelderman P, Drechsel P. Farmer perceptions and pesticide use practices in vegetable production in Ghana. Pest Management Science 2006;62:356-365.

Schaefers GA. Public sector pesticide use in Africa. Journal of Agricultural Entomology 1990;7:183-190.

Schaefers GA. Status of pesticide policy and regulations in developing countries. Journal of Agricultural Entomology 1996;13:213-222.

Sibanda T, Dobson HM, Cooper JF, Manyangarirwa W, Chiimba W. Pest management challenges for smallholder vegetable farmers in Zimbabwe. Crop Protection 2000;19:807815.

Williamson S, Ball A, Pretty J. Trends in pesticide use and drivers for safer pest management in four African countries. Crop Protection 2008;27:1327-1334. 
Table 1. Sample structure, mean farm area and mean respondent age of respondents groups from farms in Al-Batinah Governorates surveyed for pesticide disposal practices.

Number of respondents

\begin{tabular}{l|lcc|c}
\multicolumn{2}{c}{} & $\begin{array}{c}\text { Farmer Association } \\
\text { members }\end{array}$ & $\begin{array}{c}\text { Non-Farmer } \\
\text { association members }\end{array}$ & Total \\
\hline $\begin{array}{l}\text { Number of } \\
\text { respondents }\end{array}$ & Owner & 54 & 56 & 110 \\
& Worker & 52 & 51 & 103 \\
\cline { 2 - 5 } & Total number & 106 & 107 & 213 \\
\hline Mean farm & Whole sample & 17.5 & 16.0 & 16.8 \\
area (ha) & & & & 47.9 \\
\hline Mean & Owner & 45.5 & 50.1 & 39.9 \\
respondent & Worker & 39.7 & 40.1 & 44.1 \\
\cline { 2 - 5 } age (years) & Whole sample & 42.8 & 45.3 & \\
\hline
\end{tabular}


Table 2. Nationality of farm worker respondents from farms in Al-Batinah Governorates surveyed for pesticide disposal practices.

\begin{tabular}{lcc}
$\begin{array}{l}\text { Nationality of } \\
\text { farm worker }\end{array}$ & $\begin{array}{c}\text { Number of respondents } \\
\text { Farmer Association } \\
\text { members }\end{array}$ & $\begin{array}{c}\text { Non-Farmer association } \\
\text { members }\end{array}$ \\
\hline Bangladesh & 49 & 38 \\
Egypt & 1 & 4 \\
India & 2 & 2 \\
Pakistan & 0 & 5 \\
South Africa & 0 & 1 \\
Sudan & 0 & 1 \\
\hline Totals & 52 & 51 \\
\hline
\end{tabular}


Table 3. Education background of respondents from farms in Al-Batinah Governorates surveyed for pesticide disposal practices.

\begin{tabular}{l|ccccc}
\multirow{2}{*}{$\begin{array}{l}\text { Highest education } \\
\text { level gained }\end{array}$} & \multicolumn{2}{c}{ Workers } & \multicolumn{2}{c}{ Owners } & Total \\
\cline { 2 - 5 } & FA & Non-FA & FA & Non-FA & \\
\hline None & 6 & 29 & 3 & 6 & 44 \\
Elementary & 33 & 8 & 7 & 22 & 70 \\
Grade 8 & 9 & 2 & 14 & 9 & 34 \\
Grade 9 & 2 & 5 & 19 & 8 & 34 \\
Higher & 2 & 7 & 11 & 11 & 31 \\
\hline Total & 52 & 51 & 54 & 56 & 213 \\
\hline
\end{tabular}


Table 4. Pesticide risk identification by respondents from farms in Al-Batinah Governorates surveyed for pesticide disposal practices.

Figures are the percentage of respondents who identified the respective risk.

Risk identified

Workers

Owners

All
FA
Non-FA
FA
Non-FA

\begin{tabular}{lcc|cc|c}
\hline Human health & 88.5 & 35.3 & 96.3 & 92.7 & 78.4 \\
Animal health & 1.9 & 0 & 33.3 & 7.3 & 10.8 \\
Environment & 11.5 & 5.9 & 70.4 & 20.0 & 27.2 \\
Consumer & 0 & 2.0 & 0 & 1.8 & 0.9 \\
No risk & 9.6 & 64.7 & 0 & 9.1 & 20.2 \\
\hline No response & 1.9 & 0 & 0 & 0 & 0.5 \\
\hline
\end{tabular}


Table 5. Correlation matrix (Pearson) for relationship between percent responses concerning the potential risks involved in pesticide use between different farm worker/owner groups.

Workers Owners

\begin{tabular}{ll|cc|cc} 
& \multicolumn{2}{c}{ FA } & Non-FA & FA & Non-FA \\
\hline \multirow{2}{*}{ Workers } & FA & 1 & 0.336 & 0.772 & $0.996 * * *$ \\
& Non-FA & & 1 & -0.104 & 0.273 \\
\hline \multirow{2}{*}{ Owners } & FA & & & 1 & 0.826 \\
& Non-FA & & & & 1 \\
\hline
\end{tabular}

Note: Correlation did not include the 'no response' category under identified risk of Table 4. Correlation coefficients $(\mathrm{df}=3)$ were not significant at 0.05 unless indicated as follows: *** $\mathrm{P}<0.001$ 
Table 6. Methods of disposal of residual pesticide solutions and expired pesticide concentrates identified by respondents from farms in Al-Batinah Governorates surveyed for pesticide disposal practices.

Figures are the percentage of respondents who identified a particular disposal method for leftover pesticide and obsolete pesticide.

Disposal method

Workers

Owners

All

FA Non-FA FA Non-FA

\begin{tabular}{lcc|cc|c}
\hline Left-over pesticide mix & & & & & \\
$\quad$ Continue to use & 0 & 47.1 & 3.7 & 19.6 & 17.4 \\
Soil disposal & 0 & 58.8 & 3.7 & 33.9 & 23.9 \\
Mix with manure & 11.5 & 64.7 & 29.6 & 58.9 & 41.3 \\
Always use completely & 98.1 & 15.7 & 61.1 & 35.7 & 52.6 \\
Use on non-crop plants & 0 & 2.0 & 0 & 0 & 0.5 \\
\hline Obsolete pesticide stocks & 0 & & & & \\
$\quad$ Seek MAFW advice & 0 & 0 & 5.6 & 0 & 1.4 \\
Seek FA advice & 0 & 0 & 79.6 & 0 & 20.2 \\
Store & 78.8 & 5.9 & 90.7 & 14.3 & 47.4 \\
Burn with container & 0 & 5.9 & 0 & 14.3 & 5.2 \\
$\quad \begin{array}{l}\text { Municipality garbage } \\
\text { bins }\end{array}$ & 1.9 & 0 & 0 & 0 & 0.5 \\
\hline Don't use pesticides & 0 & 0 & 0 & 7.1 & 1.9 \\
\hline
\end{tabular}


Table 7. Correlation matrix for relationship between percent responses concerning the method of disposal of pesticide residues between different farm worker/owner groups.

Workers

Owners

FA Non-FA FA Non-FA

\begin{tabular}{ll|cc|cc}
\hline \multirow{2}{*}{ Workers } & FA & 1 & -0.121 & $0.687 *$ & 0.293 \\
& Non-FA & & 1 & -0.198 & $0.836^{* *}$ \\
\hline \multirow{2}{*}{ Owners } & FA & & & 1 & 0.089 \\
& Non-FA & & & & 1 \\
\hline
\end{tabular}

Note: Correlation was based up[on all the responses rows for pesticide within Table 6 with the exception of the 'don't use pesticides' category. Correlation coefficients $(\mathrm{df}=8)$ were not significant at 0.05 unless indicated as follows:

$* \mathrm{P}<0.05$

$* * \mathrm{P}<0.01$ 
Table 8. Methods of disposal of empty pesticide containers identified by respondents from farms in Al-Batinah Governorates surveyed for pesticide disposal practices.

Figures are the percentage of respondents who identified a particular disposal method for empty pesticide containers.

\begin{tabular}{lcc|cc|c} 
Disposal method & \multicolumn{2}{c}{ Workers } & \multicolumn{2}{c}{ Owners } & All \\
& FA & Non-FA & FA & Non-FA & \\
\hline Use & 0 & 0 & 0 & 0 & 0 \\
Sell & 5.8 & 41.1 & 24.1 & 19.6 & 22.5 \\
Bury & 0 & 7.8 & 0 & 3.6 & 2.8 \\
Garbage & 96.2 & 21.6 & 98.1 & 33.9 & 62.4 \\
Burn on site & 0 & 90.2 & 14.8 & 71.4 & 44.1 \\
\hline No pesticides used & 0 & 0 & 0 & 7.1 & 1.9 \\
No response & 1.9 & 0 & 0 & 0 & 0.5 \\
\hline
\end{tabular}


Table 9. Correlation matrix for relationship between percent responses concerning the method of disposal of pesticide containers between different farm worker/owner groups.

Workers

Owners

\begin{tabular}{ll|cc|cc} 
& \multicolumn{2}{c}{ FA } & Non-FA & FA & Non-FA \\
\hline \multirow{2}{*}{ Workers } & FA & 1 & -0.157 & $0.978 * *$ & 0.154 \\
& Non-FA & & 1 & 0.007 & $0.931 *$ \\
\hline \multirow{2}{*}{ Owners } & FA & & & 1 & 0.283 \\
& Non-FA & & & & 1 \\
\hline
\end{tabular}

Note: Correlation was based upon all the responses rows for container disposal in Table 8 ws with the exception of the 'no pesticides' and 'no response' categories. Correlation coefficients $(\mathrm{df}=3)$ were not significant at 0.05 unless indicated as follows:

$* \mathrm{P}<0.05$

$* * \mathrm{P}<0.01$ 
Figure 1. Map of northern Oman showing North and South Al-

Batinah Governorates.

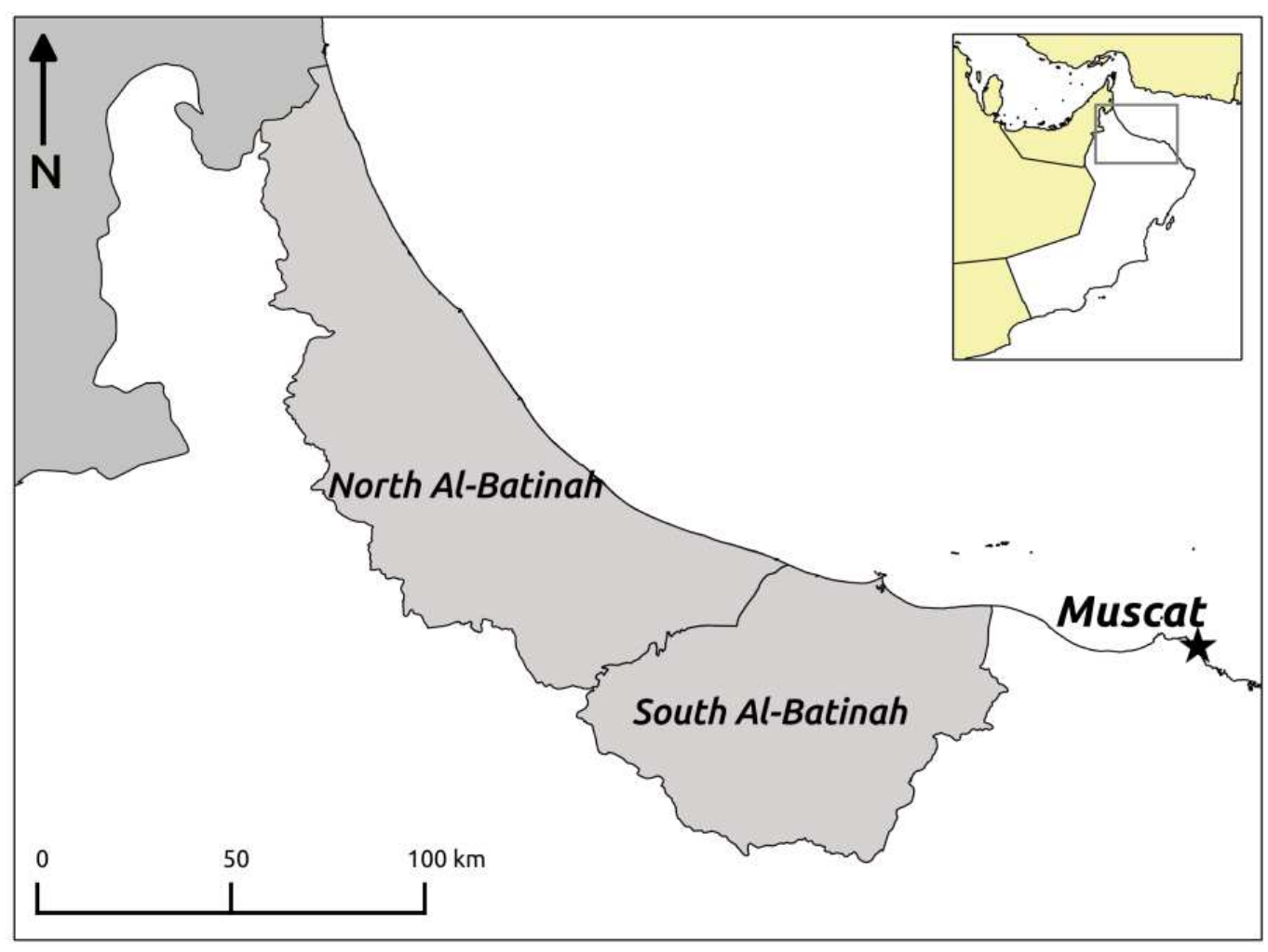

